\title{
Cavity Nest Materials of Northern Flying Squirrels, Glaucomys sabrinus, and North American Red Squirrels, Tamiasciurus hudsonicus, in a Secondary Hardwood Forest of Southern Ontario
}

\author{
Jesse E. H. Patterson ${ }^{1,3}$, Stephen J. PATterson ${ }^{2}$, and Jay R. MAlcolm ${ }^{1}$ \\ ${ }^{1}$ Faculty of Forestry, University of Toronto, 33 Willcocks Street, Toronto, Ontario, M5S 3B3 Canada \\ ${ }^{2}$ Hummingbird Services, 251 Queen Street South, Suite 523, Streetsville, Ontario, L5M 1L7 Canada \\ ${ }^{3}$ Present address: Department of Biological Sciences, University of Calgary, 2500 University Drive, Calgary, Alberta T2N 1N4 \\ Canada
}

Patterson, Jesse E. H., Stephen J. Patterson, and Jay R. Malcolm. 2007. Cavity nest materials of Northern Flying Squirrels, Glaucomys sabrinus, and North American Red Squirrels, Tamiasciurus hudsonicus, in a secondary hardwood forest of southern Ontario. Canadian Field-Naturalist 121(3): 303-307.

Through deployment of artificial nest boxes, we examined the composition of cavity nest materials used by Northern Flying Squirrels (Glaucomys sabrinus) and North American Red Squirrels (Tamiasciurus hudsonicus) in a secondary hardwood forest of southern Ontario, Canada. We collected 32 nests of known species association and found that $85.7 \%$ of G. sabrinus nests and $77.8 \%$ of $T$. hudsonicus nests were constructed almost entirely of shredded bark from Eastern White Cedar (Thuja occidentalis). Mean nest depth across all samples was $12.2 \mathrm{~cm}$ and showed no significant difference between species or between spring and summer nests. We review the antiparasitic properties of T. occidentalis and suggest that the use of shredded cedar bark by $G$. sabrinus and $T$. hudsonicus to line nest cavities may be a behavioural adaptation, which reduces ectoparasite loads in the nest environment.

Key Words: Northern Flying Squirrel, Glaucomys sabrinus, North American Red Squirrel, Tamiasciurus hudsonicus, ectoparasites, nest box, nest material, nest-protection hypothesis, thermoregulation, Eastern White Cedar, Thuja occidentalis, Ontario.

Tree cavities are a critical resource for many tree squirrels in forest ecosystems, providing sites for raising young, avoiding predators, and improving thermoregulation (Collias 1964; Weigl 1978; Wiebe 2001). Tree cavities are generally most abundant in old growth forests where large diameter trees and well-decayed snags are commonplace (Holloway and Malcolm 2006; Holloway and Malcolm 2007). Cavities also may form in live trees where the entry of rot has been facilitated by disease, deformities, broken limbs or woodpecker excavations. Where tree cavities are not readily available, many tree squirrels use external nests (dreys) or subterranean nests, although evidence is emerging that tree cavities are preferentially selected when available (Bakker and Hastings 2002). Nest materials used in cavity nest construction may not only act to increase ambient temperature in the nest environment and provide comfort for nest occupants, but may also reduce ectoparasite loads and repel moisture in these dark, damp microclimates (Stapp et al. 1991; Hemmes et al. 2002.) However, despite their importance, tree cavities and cavity nests are rarely incorporated into studies of tree squirrels (Fokidis and Risch 2005).

The nocturnal Northern Flying Squirrel (Glaucomys sabrinus) and the diurnal North American Red Squirrel (Tamiasciurus hudsonicus) are both occasional cavity nesting, arboreal rodents common in temperate and boreal forests of North America. Both species are primarily associated with conifer-dominated forests, although in many areas of eastern North America they inhabit hardwood and mixed hardwood-conifer forests
(Flyger and Gates 1982; Holloway and Malcolm 2006; Patterson 2008). Both G. sabrinus and T. hudsonicus have been found to use cavities in trees more intensively than external or subterranean shelters, especially for natal nests (Layne 1954; Bakker and Hastings 2002; Holloway and Malcolm 2007).

Nest materials used by arboreal squirrels have been found to vary geographically (Muul 1974). However, most reports describing nest materials employed by squirrels have been qualitative in nature and have focused on dreys. Tamiasciurus hudsonicus dreys have been noted to include grape bark, deciduous leaves, dried grasses, moss, feathers, fur and soft inner bark (Layne 1954). Similarly, dreys of G. sabrinus have been found to consist of dried grasses, shredded bark, mosses, twigs and lichens (Rust 1946; Mowrey and Zasada 1984). Cavity nests have been described quantitatively only once for $G$. sabrinus (Hayward and Rosentreter 1994). Using nest boxes, these authors found that $G$. sabrinus in the northern Rocky Mountains of central Idaho and western Montana primarily constructed cavity nests from arboreal lichens, especially of the genera Bryoria and Letharia. We are not aware of studies that have quantified cavity nest materials of $T$. hudsonicus; however, Hayward and Rosentreter (1994) suggest a preference for grasses and shredded bark. Published data on G. sabrinus and T. hudsonicus nest materials, and associated seasonal differences and depths, in the Great Lakes-St. Lawrence forest region of eastern North America do not exist. In general, the study of nest material use and function in mammals has 
received very little attention by researchers and thus warrants investigation.

In order to gain a more complete understanding of the habitat requirements for G. sabrinus and T. hudsonicus in northern secondary hardwood forests, we characterize cavity nest materials used by these two species in a large network of nest boxes in southern Ontario, Canada. We hypothesized that $G$. sabrinus and $T$. hudsonicus would preferentially select nest materials that favoured cavity nest occupation (i.e., parasite reduction, moisture repellency). Nest depth measurements were investigated as a function of the type of nest material and season (spring and summer); we also assessed seasonal variation in nest material composition. We predicted that nest depths would exhibit interseasonal variability if nest construction was primarily to enhance thermoregulation, such that deeper nests would be constructed under colder temperature regimes. Given the prevalence of shredded cedar bark in the nests of both G. sabrinus and T. hudsonicus, we discuss the potential antiparasitic and thermoregulatory benefits of Eastern White Cedar (Thuja occidentalis) bark.

\section{Study Area}

The study was conducted in Bruce and Grey counties, Ontario, Canada $\left(43^{\circ} 59^{\prime}\right.$ to $45^{\circ} 12^{\prime} \mathrm{N}, 80^{\circ} 22^{\prime}$ to $\left.81^{\circ} 39^{\prime} \mathrm{W}\right)$, which together encompass an area of about $22000 \mathrm{~km}^{2}$. Nest boxes were placed in trees growing at various elevations, ranging from approximately $200 \mathrm{~m}$ to $450 \mathrm{~m}$ above sea level. Approximately $22 \%$ of the landscape is currently composed of closed-canopy secondary forests, which are dominated by Sugar Maple (Acer saccharum), White Ash (Fraxinus americana) and American Beech (Fagus grandifolia). Other common tree species include Eastern White Cedar, Eastern Hemlock (Tsuga canadensis), aspen (Populus tremuloides, $P$. grandidentata) and White Birch (Betula papyrifera) (Patterson 2008). Small stands of Eastern White Pine (Pinus strobus) and spruce (Picea glauca, $P$. mariana, $P$. rubens) occur throughout the area, often in plantations.

\section{Materials and Methods}

A total of 266 nest boxes were installed between 2002 and 2004 as part of a larger study being conducted by SJP on G. sabrinus. Sampling effort varied among years due to logistical constraints. In 2002, 154 boxes were installed; an additional 36 boxes were installed in 2003 and the final 76 boxes were installed in 2004 . All nest boxes were placed at heights of 3-4.5 m on trees that had a diameter at breast height $>17 \mathrm{~cm}$. Following Carey (2002), nest boxes were established at a density of three nest boxes/ha to allow for a balance between occupancy rates and monitoring effort. Three or more boxes were placed at each of 70 sites across the study region.

Boxes were constructed following Sonenshine et al. (1973), except for the door which was top mounted and could be flipped up to remove any animals and nest material. Our entrance hole was also of larger diameter $(4 \mathrm{~cm})$ to permit use by G. sabrinus and $T$. hudsonicus, but exclude Eastern Grey Squirrels (Sciurus carolinensis). All boxes were mounted to the tree trunk and any tree branches were removed from below the nest box.

All boxes were intensively checked twice per year during the day: once in the spring and once again in autumn. Spring checks were conducted between 12 May and 12 June following the onset of parturition, whereas autumn checks were conducted between 12 October and 12 November. Cursory visual nest box inspections were conducted monthly to monitor the condition of the boxes, but no sampling was done on these occasions. These visual inspections indicated that neither G. sabrinus nor T. hudsonicus used the nest boxes in late autumn and winter (early December late February), presumably because individuals abandoned the nest boxes for larger, better insulated natural cavities or subnivean nests. Therefore, nests found at the spring inspection had been constructed between early March and the date of inspection in spring (hereafter termed "spring" nests), whereas those found at the autumn inspection had been constructed between the spring and autumn inspection dates (hereafter termed "summer" nests). Where nests were present and occupied at time of inspection, we recorded the location, number and reproductive condition of occupants and nest depth. Samples of nest material were collected from all nests for identification of materials. In cases where the nest box was not occupied at the time of inspection, the entire nest was removed. In cases where the nest box was occupied at the time of inspection (14\% of the nests), a small sample of nest material was initially removed and the entire nest was subsequently removed during targeted monthly nest box examinations following the departure of nest occupants. We removed nest material not only to examine nest materials, but also because Hayward and Rosentreter (1994) observed that nest boxes were typically not occupied in successive years if used nest material was present. Nest depth was always determined during the initial investigation and measured in situ along the vertical dimension from the internal base of the nest box to the top of the nest. Nest volume was determined by multiplying the nest depth by the internal width and length dimensions of the nest box.

\section{Results}

Nest Box Occupation

Between 2002 and 2005, we found 224 occupied and unoccupied nests. Of these, 32 were occupied when checked (14 G. sabrinus and 18 T. hudsonicus). Females were found occupying the nest boxes in 12 cases for $G$. sabrinus and 14 cases for T. hudsonicus. Lone males were occasionally found occupying the nest boxes (two G. sabrinus and four T. hudsonicus). 
Nest Materials of G. sabrinus and T. hudsonicus

Twelve of the 14 boxes occupied by $G$. sabrinus and 14 of the 18 boxes occupied by $T$. hudsonicus contained $>90 \%$ shredded cedar bark by volume. One $G$. sabrinus nest was composed entirely of fibreglass insulation and another was composed of $>80 \%$ shredded deciduous bark. Trace amounts of peat moss, dried grasses, cedar leaves and twigs also were found in occupied G. sabrinus nests. Two T. hudsonicus nests were composed entirely of dried grasses and two nests contained $>80 \%$ deciduous leaves. Trace amounts of shredded plastic, bird feathers, animal fur, dried grasses and deciduous leaves also were found in occupied T. hudsonicus nests.

Nest materials did not appear to differ between seasons $(t=-1.892, P=0.06)$, with shredded cedar bark appearing as the most prominent nest material in both spring $(84.5 \%)$ and summer $(79.3 \%)$. Small sample sizes for male nests did not allow for robust comparisons between male and female nest materials.

\section{Nest Depth}

Mean depth of nests occupied by G. sabrinus was $12.1 \mathrm{~cm}(\mathrm{SD}=2.4$, range $=6.7$ to $15.3 \mathrm{~cm})$ and for $T$. hudsonicus was $12.3 \mathrm{~cm}(\mathrm{SD}=2.1$, range $=9.1$ to $17.8 \mathrm{~cm})$, although the difference was not statistically different $(t=0.31, P=0.76)$. We found no statistical difference between spring (G. sabrinus mean $=11.9 \mathrm{~cm}$; T. hudsonicus mean $=12.6 \mathrm{~cm})$ and summer $(G$. sabrinus mean $=11.1 \mathrm{~cm} ;$ T. hudsonicus mean $=12.7 \mathrm{~cm})$ nest depths for either species for occupied nests $(G$. sabrinus: $t=0.55, P=0.30 ;$ T. hudsonicus: $t=0.17$, $P=0.43$ ). Small sample sizes for male nests did not allow for robust comparisons between male and female nest depths.

\section{Discussion}

The prominence of cedar bark in G. sabrinus and T. hudsonicus nests may be explained by at least two, nonmutually exclusive, hypotheses: nest-protection and thermoregulation. The nest-protection hypothesis has received much attention from ornithologists to explain the use of green vegetation in avian nests. Initially suggested by Wimberger (1984) and tested by Clark and Mason (1985), the nest-protection hypothesis posits that animals exploit the antiparasitic properties of certain plant species that emit specific volatile compounds (Dawson 2004). All plants contain secondary metabolites that are used as a defense against disease and herbivory (Clark and Mason 1988) and, when these plants are used as nesting materials, certain compounds may reduce ectoparasite loads in the nest environment. Numerous studies have supported the nestprotection hypothesis in birds (Wimberger 1984; Rodgers et al. 1988; Fauth et al. 1991; Lafuma et al. 2001). The nest protection hypothesis has found support on at least one occasion for small mammals: Hemmes et al. (2002) reported that Dusky-footed Wood Rats (Neotoma fuscipes) placed California Bay
(Umbellularia californica) leaves around their nest sites. Laboratory tests revealed that when incubated with torn $U$. californica leaves for $72 \mathrm{~h}$, survival of flea larvae was reduced by $74 \%$ compared to controls. By using shredded Eastern White Cedar bark as a primary nest material, G. sabrinus and T. hudsonicus also may be limiting exposure to nest-borne ectoparasites. Phytochemical analysis of $T$. occidentalis bark has revealed 22 volatile compounds, including monoterpenes, fenchene, camphene, camphor, carvacol and paracymene (Shaw 1953; Witte et al. 1983; Yatagai et al. 1985; Keita et al. 2001), several of which have noted antiparasitic or insecticidal properties (Adams et al. 1988; Adams 1993; Keita et al. 2001).

Support for the nest protection hypothesis is bolstered by the use of lichens in nests of G. sabrinus found in western North America. Antiparasitic effects have been described for several species of lichen. Hayward and Rosentreter (1994) found that G. sabrinus selected lichens containing the secondary compounds norstictic acid, fumarprotocetraric acid, vulpinic acid and atranorin, all of which have been attributed with varying degrees of antiparasitic or antimicrobial effects (Giez et al. 1994; Tay et al. 2004; Yilmaz et al. 2004). These various studies support the possibility that the use of T. occidentalis, as well as several lichen species, by $G$. sabrinus and T. hudsonicus may be a behavioural adaptation for ectoparasite control in the nest environment. Further testing of the antiparasitic effects of $T$. occidentalis volatile oils and secondary compounds on known G. sabrinus and T. hudsonicus ectoparasites is required.

An alternative hypothesis is that shredded cedar bark may offer greater insulative properties than other available materials. Hayward and Rosentreter (1994) suggested the same hypothesis when characterizing the primary use of lichens as nest material by G. sabrinus. This hypothesis is based on the finding by Stapp et al. (1991) that nests composed of plant fibres allowed Southern Flying Squirrels (Glaucomys volans) to reduce their energy expenditure when experimentally subjected to cold temperatures. We are not aware of studies on the thermal properties of cedar bark, lichens or other nest materials found in this study. A common assumption is that nest materials with greater thermal properties are favoured, and/or that nest depth would peak, during colder periods. Contrastingly, we found that shredded cedar bark was used equally in spring and summer and that nest depth did not vary between the two seasons. This suggests that cedar bark may not be chosen solely for thermoregulatory purposes; however, we are unable to reject the thermoregulation hypothesis outright without further empirical testing.

We dismiss a third potential hypothesis that squirrels choose the most widely and readily available materials for use as nest substrate. Patterson (2008) found that deciduous trees accounted for approximately $80 \%$ of the tree composition in our study area by basal area, 
while Eastern White Cedar accounted for less than $10 \%$ of the total forest composition on average, by basal area. Deciduous leaves and deciduous tree bark are therefore more greatly available than $T$. occidentalis bark in our study area. At some sites where cedar bark nest material was found to occur, Eastern White Cedar trees accounted for only $2 \%$ or less of the total tree composition (Patterson 2008). On one occasion during this study we observed a single female $G$. sabrinus travel over $500 \mathrm{~m}$ to the nearest $T$. occidentalis tree to acquire cedar bark for nest construction. Mosses, lichens, and grasses are also widely available throughout the study area (J. Patterson, unpublished data) and yet were rarely found as nest materials in this study.

\section{Acknowledgments}

We thank the Grey Sauble Conservation Authority, the Saugeen Valley Conservation Authority and the various private landowners who graciously made their land available for this study. We also would like to thank Thistlewood Timber Frame Homes in Markdale, Ontario, for generously donating the lumber used for the nest boxes. J. Bowman, D. Nagorsen and two anonymous reviewers provided helpful suggestions for the improvement of this manuscript. We appreciate the support and field assistance provided by H. Maddin and M. Patterson. This project was funded, in part, by the Natural Sciences and Engineering Research Council of Canada Undergraduate Student Research Award to JEHP.

\section{Literature Cited}

Adams, R. P. 1993. Cedar wood oil - analysis and properties. Pages 159-173 in Essential oils and waxes. Edited by $\mathrm{H}$. F. Linskens and J. F. Jackson. Springer-Verlag, New York, New York.

Adams, R. P., C. A. McDaniel, and F. L. Carter. 1988. Termiticidal activities in the heartwood, bark/sapwood and leaves of Juniperus species from the United States. Biochemical Systematics and Ecology 16: 453-456.

Bakker, V. J., and K. Hastings. 2002. Den trees used by northern flying squirrels (Glaucomys sabrinus) in southeastern Alaska. Canadian Journal of Zoology 80: 16231633.

Carey, A. B. 2002. Response of northern flying squirrels to supplementary dens. Wildlife Society Bulletin 30: 547556.

Clark, L., and J. R. Mason. 1985. Use of nest material as insecticidal and anti-pathogenic agents by the European starling. Oecologia 67: 169-176.

Clark, L., and J. R. Mason. 1988. Effect of biologically active plants used as nest material and the derived benefit to starling nestlings. Oecologia 77: 174-180.

Collias, N. E. 1964. The evolution of nests and nest building in birds. American Zoologist 4: 175-190.

Dawson, R. D. 2004. Does fresh vegetation protect avian nests from ectoparasites? An experiment with tree swallows. Canadian Journal of Zoology 82: 1005-1010.
Fauth, P. T., D. G. Krementz, and J. E. Hines. 1991. Ectoparasitism and the role of green nesting material in the European starling. Oecologia 88: 22-29.

Flyger, V., and J. E. Gates. 1982. Pine squirrels Tamiasciurus hudsonicus and T. douglasii. Pages 230-238 in Wild mammals of North America: biology, management, and economics. Edited by J. A. Chapman and G. A. Feldhamer. The Johns Hopkins University Press, Baltimore.

Fokidis, H. B., and T. S. Risch. 2005. The use of nest boxes to sample arboreal vertebrates. Southeastern Naturalist 4: 447-458.

Giez, I., O. L. Lange, and P. Proksch. 1994. Growth retarding activity of lichen substances against the polyphagous herbivorous insect Spodoptera littoralis. Biochemical Systematics and Ecology 22: 113-120.

Hayward, G. D., and R. Rosentreter. 1994. Lichens as nesting material for northern flying squirrels in the northern Rocky Mountains. Journal of Mammalogy 75: 663-673.

Hemmes, R. B., A. Alvarado, and B. L. Hart. 2002. Use of California bay foliage by wood rats for possible fumigation of nest-borne ectoparasites. Behavioural Ecology 13: 381385.

Holloway, G. L., and J. R. Malcolm. 2006. Sciurid habitat relationships in forests managed under selection and shelterwood silviculture in Ontario. Journal of Wildlife Management 70: 1735-1745.

Holloway, G. L., and J. R. Malcolm. 2007. Nest-tree use by northern and southern flying squirrels in central Ontario. Journal of Mammalogy 88: 226-233.

Keita, S. M., C. Vincent, J. P. Schmidt, and J. T. Arnason. 2001. Insecticidal effects of Thuja occidentalis (Cupressaceae) essential oil on Callosobruchus maculatus [Coleoptera: Bruchidae]. Canadian Journal of Plant Science 81: 173-177.

Lafuma, L., M. M. Lambrechts, and M. Raymond. 2001. Aromatic plants in bird nests as a protection against bloodsucking flying insects? Behavioural Processes 56: 113-120.

Layne, J. N. 1954. The biology of the red squirrel, Tamiasciurus hudsonicus loquax (Bangs), in central New York. Ecological Monographs 24: 227-268.

Mowrey, R. A., and J. C. Zasada. 1984. Den tree use and movements of northern flying squirrels in interior Alaska and implications for forest management. Pages 351-356 in Fish and wildlife relationships in old-growth forests: proceedings of a symposium. Edited by W. R. Meehan, T. R. Merrell, and T. A. Hanley. American Institute of Fisheries Research Biology, Moorhead City, North Carolina.

Muul, I. 1974. Geographic variation in the nesting habits of Glaucomys volans. Journal of Mammalogy 55: 840-844.

Patterson, J. E. H. 2008. Forest fragmentation effects and the cavity nest material requirements of northern flying squirrels and red squirrels in a fragmented secondary hardwood forest region of Ontario, Canada. MSc thesis, University of Toronto, Toronto, Ontario, Canada. 106 pages.

Rodgers, J. A., Jr., A. S. Wenner, and S. T. Schwikert. 1988. The use and function of green nest material by wood storks. Wilson Bulletin 100: 411-423.

Rust, H. J. 1946. Mammals of northern Idaho. Journal of Mammalogy 27: 308-327.

Shaw, A. C. 1953. The essential oil of Thuja occidentalis. Canadian Journal of Chemistry 31: 277-281.

Sonenshine, D. E., D. G. Cerretani, G. Enlow, and B. L. Elisberg. 1973. Improved methods for capturing wild flying squirrels. Journal of Wildlife Management 37: 588-590. 
Stapp, P., P. J. Pekins, and W. W. Mautz. 1991. Winter energy expenditure and the distribution of southern flying squirrels. Canadian Journal of Zoology 69: 2548-2555.

Tay, T., A. O. Turk, M. Yilmaz, H. Turk, and M. Kivanc. 2004. Evaluation of the antimicrobial activity of the acetone extract of the lichen Ramalina farinacea and its (+)usnic acid, norstictic acid, and protocetraric acid constituents. Zeitschrift für Naturforschung C-A Journal of Biosciences 59: 384-388.

Weigl, P. D. 1978. Resource overlap, interspecific interactions and the distribution of the flying squirrels, Glaucomys volans and $G$. sabrinus. The American Midland Naturalist 100: 83-96.

Wiebe, K. L. 2001. Microclimate of tree cavity nests: is it important for reproductive success in northern flickers? Auk 118: 412-421.
Wimberger, P. H. 1984. The use of green plant material in bird nests to avoid ectoparasites. Auk 101: 615-618.

Witte, L., J. Berlin, V. Wray, W. Schubert, W. Kohl, G. Hofle, and J. Hammer. 1983. Mono- and diterpenes from cell cultures of Thuja occidentalis. Planta Medica 49: 216-221.

Yatagai, M., T. Sato, and T. Takahashi. 1985. Terpenes of oils from Cupressaceae. Biochemical Systematics and Ecology 13: 377-385.

Yilmaz, M., A. O. Turk, T. Tay, and M. Kivanc. 2004. The antimicrobial activity of extracts of the lichen Cladonia foliacea and its (-)usnic acid, atranorin, and fumarprotocetraric acid constituents. Zeitschrift für Naturforschung C-A Journal of Biosciences 59: 249-254.

Received 12 February 2007

Accepted 10 April 2008 